\title{
System concept of experience in nautical tourism
}

\author{
R. Franjić ${ }^{1}, \mathrm{~S}$. Favro $^{2} \&$ M. Perišic ${ }^{3}$ \\ ${ }^{1}$ Tourism Studies, University of Applied Sciences VERN, Zagreb, Croatia \\ ${ }^{2}$ Hydrographic Institute of the Republic of Croatia, Split, Croatia \\ ${ }^{3}$ Plovput d.o.o., Split, Croatia
}

\begin{abstract}
The objective of this paper is to explain how to create an experienced based concept to attract new tourists and to create at least a memorable experience with these consumes and to analyze the importance of animators in tailoring experiences in destinations. In such, the role of animators in nautical tourism is vital for creating memorable experiences desired and sought by tourists. The local population should have a possibility of being educated about local differences and tourist workers should be additionally educated. The result would be the degree of professional development needed so the tourist workers could enrich the tourist product of a nautical destination, and also gaining on the interpretation quality. New ways of communication are needed to create longlasting commitments with individuals and target groups. In a tourist world where people are more and more driven by self expressional values instead of survival values, we need an additional way of engineering. We need Imagineering engineering for imagination, to realize the challenges of the experience economy. Imagineering is about managing the relationship with the costumer, based on an experiential system concept that affect 'fans' in the heart, that will be translated in an experiential world in all contact moments with the guest. In short it's about using experiences, which can reach, touch, affect and fascinate the guest in marinas and small ports permanently. Imagineering has three elements: story, vision, and guidance. In this paper Imagineering will be presented as a powerful solution for nautical tourist destinations to create long-lasting emotional bond with individual guests.

Keywords: experience economy, imagineering, integral experiential concept, nautical tourist destination, animator.
\end{abstract}




\section{Introduction}

Many contemporary views on the future of technology and business put the individual and his experience first. The rising affluence and growing transience of people, places, things that created the material basis for today's global, informational and networked society, it is argued, has led to an even greater change that occurs deep inside people's minds that is slowly affecting society and the economy at large: The existential view of life is shifting from a largely externally oriented view towards a more and more internally oriented view. It no longer affects only the outside world, but also our inner selves, our experience that is driving our decisions and therefore shaping our consumption patterns. The economy transforms into an experience economy in order to support more and more people in their need towards psychological self-determination and wellbeing.

In a creative economy there is a growing need for high level professionals who can create and innovate value from the experience perspective. Nowadays, people are driven much more by values of self-expression rather than those of rudimentary survival. They have a deep need to make sense of their lives in ways that are unique and personal. One of the most distinct ways in which this is manifested, is the new individual's consumption pattern - by means of their choices they create their own identity. In our society, consumption is an absolute necessity, not a luxury. Experience management is seen as the way to remain competitive in markets where global competition and internet technology have turned products and services into commodities, bought and sold on price alone. There is also a growing research interest in understanding the individual consumer's experience, drawing on behavioral, sociological and ethnographical approaches. Both the managerial and consumer perspectives see the goal of extraordinary experiences as personal growth and fulfillment. It is by providing a stage or space for this to happen that a company can attract and retain its customers. The growing relation between "market share" and "heart share" forces companies to formulate a "split vision": simultaneously focusing on information and imagination, on reason and emotion. The addition of emotional possibilities expands the scope for competition. Beginning with the assumption that in order for sustainable tourism to work the local community is essential for the interpretation of intangible traditional cultural heritage, this paper will follow by showing how to construct a sustainable system of its interpretation. By doing so it will emphasize the importance of animation in the development of such a system and it will also show how the typology of interpretation is dependent on the typology of the local community.

\section{Experience management}

Sustainable competitive advantage can only be gained by giving the customer a unique and memorable experience (Pine and Gilmore [1]). This is done through treating 'work as theatre and every business a stage'. As this paper will show, this draws on Performance Theory (Schechner [2]) and the service-as-drama 
metaphor (Grove et al. [3]). Their approach has led to a growing number of management books on how to make the customer experience the centre of the organization's strategic planning, marketing and operations (Shaw [4]), (Smith and Wheeler [5]). The growth of Experiential Marketing is also significant for our sectors through the increased use of corporate hospitality and events, sports and arts sponsorship to associate brands with memorable experiences involving the senses and the emotions. Some writers (e.g. Nijs [6], Prahalad and Ramaswamy [7]) has criticized the emphasis on staging performances as superficial and product-centered and call for a more strategic approach based on shared values, allowing the customer to create their own experiences in a search for personal growth. In this way the management strand is converging with the consumer strand.

\section{Consumer experience vs. transformational experience}

On the consumer side, a focus on experiences has arisen in response to the limitations of seeing consumer behavior purely in terms of cognitive information processing. Experiences are subjective, emotional states laden with symbolic meaning (Hirschman and Holbrook [8]). Consumption is hedonic not utilitarian, particularly in leisure situations.

A distinction is often made between everyday and extraordinary experiences (Abrahams [9]). Many of the products in tourism and leisure involve skilled consumption (Scitovsky [10]), physical or intellectual challenge and the sharing of experience with a community of like-minded people (Beard and Ragheb [11]). The desired effect is the state of absorption in the activity [12] calls Energy Flow and motivation is a complex mixture of escapism, socialization and selfactualization (Ryan [13]).

Where the managerial and consumer perspectives converge is in their view of consumer satisfaction as something that emerges over the course of the whole experience, rather than as a response to individual attributes of the service. This requires new forms of research such as Experience Mapping (Schmitt [14]) or theatrical scripting (Harris et al. [15]) of the critical moments of truth (Carlzon [16]). Ethnographic and narrative research (e.g. Arnould and Price [17]) are more likely to provide insights than quantitative methods.

As the ecology in biology is complicated and multidimensional, so is also the ecology of producing human experiences and transformations. We need to understand the different dimensions and parameters to manage and produce successful transformational experiences. To do this we need a clear conceptualization and frameworks of both the temporal and spatial context of the transformational offerings and processes. The transformative goals must consist of emotional, cognitive and behavioral transformations towards a sustainable lifestyle and sustainable values. This transformational experience has to be based on tourist participation and involvement in the experience product development process (Boswijk et al. [18]) suggested co-creation and self-direction development of experience production. 


\section{Experience Pyramid - Implementation of Transformational Experience Production (TEP)}

Tourism and leisure industry in general, were faced with an emotion demand at the time of their initiation. The specific set of instruments that is applied in the world of tourism to respond to the emotion demand is referred to as "Imagineering" and "engineering" for "imagination". Imagineering is the art of management to combine soul and professionalism into "inspiring" business operations. Similar to marketing, it is a set of instruments that can be used to achieve commercial and social objectives. Contrary to marketing, it is not the customer/guest who constitutes the starting and end point, but a "creative thought" or a "vision statement" (the soul) of the company or organization.

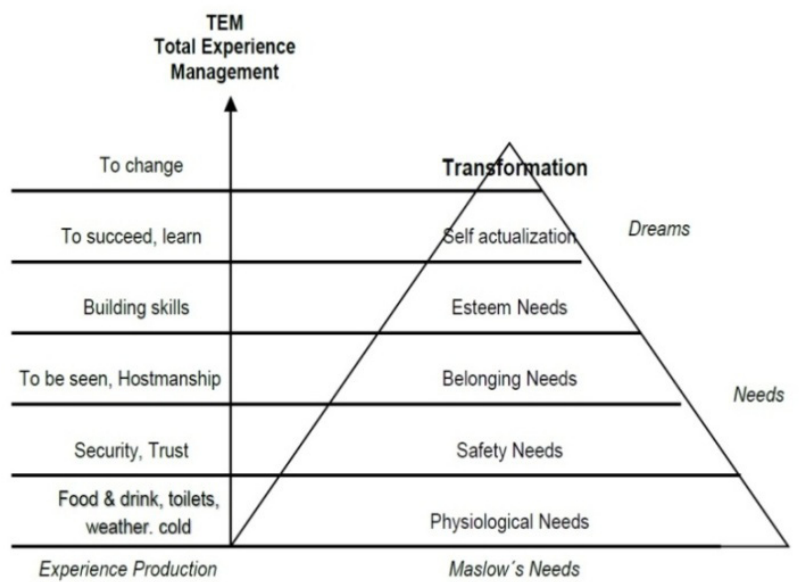

Figure 1: Integrating Maslow's human needs into experience production.

Instead of using Maslow's hierarchy of needs for understanding guest Experiences, in this way is proposed using his concept in a production perspective (Gelter [19], Gelter [20]). In taking account all the levels of the "Pyramid of Needs", the Experience Producer approaches a "Total Experience" concept when incorporating not only human need dimensions but also human dream dimensions (as proposed by Jensen [21]). Using this theoretical concept for Experience production, the producer can easily construct a check-list for each level at each dramaturgical stage of the production, a kind of TEM protocol for Experience Production. This TEM-model also gives a base for the diagnosis of aspirants for personal transformation offerings which according to this model are based both on basic needs such as security, thrust, esteem etc. as well on personal dreams, goals of learning and changing. Thus when designing a transformational offering, this TEM concept can be useful.

The next model is based on synthesis on various previous writings concerning the topic (Tarssanen and Kylänen [22]). The Pyramid approach suggests that the 
product should include six elements for being experiential: individuality, authenticity, story, multi-sensory perception, contrast and interaction. Through these elements customer's experience proceeds from motivational level to physical, intellectual and emotional, even spiritual levels. Model represents an ideal type - the 'perfect product' in which every element of experience is reflected on the motivational, mental and physical levels. It is an explicit tool for finding critical points, qualities or deficiencies in the product. With the model service provider can analyze one's product and discover ways to develop it (Tarssanen and Kylänen [22]). Experience Pyramid has been successfully applied when developing various tourist experiences in Finnish Lapland and in Norway. It is currently used as a main framework in LCEEI's product development services.

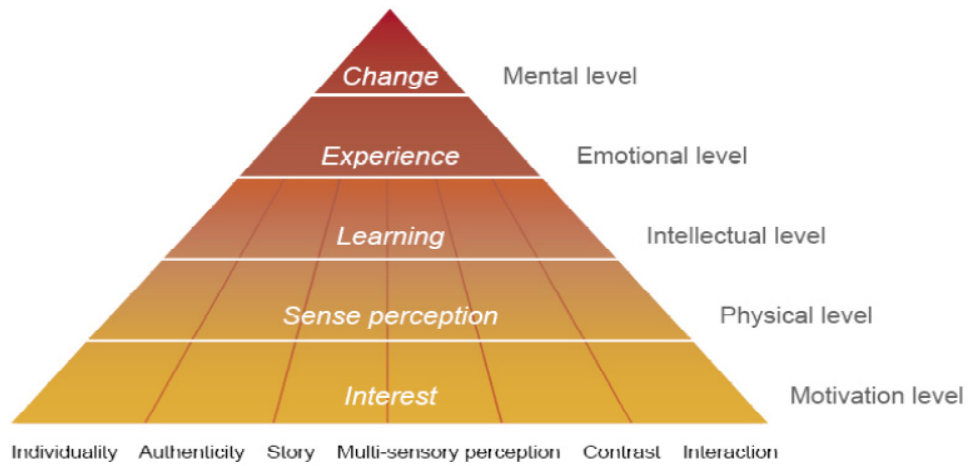

Figure 2: $\quad$ Experience pyramid.

\section{The interpretation of traditional maritime cultural heritage through the use of experience pyramid}

It is precisely the preservation of traditional characteristics of the maritime Mediterranean space which determines the extent of their touristic attraction. Tourists will not visit maritime areas and settlements which retained none of their traditional ways of life and work. It must also be emphasized that the preservation of natural beauty is also a part of the maritime tradition. The maritime space offers specific and unusual touristic experiences precisely on the basis of tradition (Kozličić [23]).

It is necessary to establish a functional and meaningful relationship between the presented architecture and the habits of people who lived in the past, their material and spiritual world. Each specific building material or technical solution (for example, the šterne [wells], the kažuni [shelters made out of stone blocks], the hollowed-out wooden gutters, the small windows, the škure [wooden shutters], etc.) must speak of the man who lived here many years ago, of his knowledge, abilities, habits and culture. 
What links together space and time with today's visitor/tourist is the correct interpretation, because a story awakens emotions and a proficient interpreteranimator can reconstruct history through his story and create the power of the present moment. Visitors/tourists want to draw parallels with the contemporary world and their own life with regards to certain touristic attractions. They want to actualize the experiences from the past. The interpreter-animator must help them to do this. The classic form of guiding through explanations and demonstrations offers discussion as another method of learning.

Traditional crafts are a part of cultural heritage. They used to be defined in museums as material facts, through objects which testified of their existence. Today, with a new sensitivity for goals, we know that the more important part is the one which hides within the concept of the object, in the process which created it. The object is only the aftermath of ideas, technologies and skills realized in the process ("know-how") (Šola [24]). "Traditional crafts are crafts which require specific knowledge of craft skills and the ability to carry out tasks which consist mostly of manual labour, and which in regards to the technology of manufacture, work, purpose and shape depend on traditional culture forms and in that sense they can symbolize the local, regional or national identity. Artistic crafts are crafts which are distinguished by products and services of a high esthetical value, design, artistic and other solutions, along with emphasized creativity and individuality of the master craftsman-artist." A craft is an activity which in general involves specific skills passed on through apprenticeship to a master craftsman. A craft is a skill, especially one which includes practical skills, and it can refer to an occupation or an individual skill. When one mentions "traditional crafts," the common reaction is to think of endangered trades. The means and ways of achieving that the intangible cultural heritage reaches tourists in a correct way is through animation which is given the task of organizing and carrying through the experience. The animators become managers who guide the experience and the emotions and they try to keep the guest from feeling a sense of detachment during his stay at the touristic destination.

Today, touristic tours on the Turkish coast apart from visits to Antic localities also include visits to dozens of small shipyards which are in the business of building wooden touristic ships (gullets) using modernized traditional procedures and tools. The direct contact of the tourist with traditional shipbuilding and the subsequent cruise present an opportunity of personally experiencing an Antic touristic story.

Popular representations of history are currently taking on new forms, and reaching wider audiences than ever before (Oesterle [25]). Prominent among the phenomena are themed environments that attempt to present histories and cultural traditions for consumption to paying customers. Themed environments themselves come in a variety of formats: theme parks on a wide variety of topics attract many visitors, the more traditional open air museums are increasingly taking to embellishing their presentations with living history shows. Re-enacting all sorts of historical periods is a popular hobby, and so-called medieval markets and music groups draw crowds. As globalized forms of cultural display, these 
phenomena are singularly effective and continue to puzzle historians, ethnographers, cultural and media analysts alike.

Using the concepts of "pastness" and "placemaking", the issue of theming is addressed from an archaeological perspective (Holtorf [26]). From his point of view, "pastness" is not based on the actual age of the presented material or buildings, but rather relies on material clues, overarching design elements and visitor pre understandings. "Placemaking", on the other hand, is the process by which these stereotypical collective memories are turned into material objects. Holtorf discussed specifically whether or not a meaningful experience of the collective past (real or imagined) required a minimum of genuine materiality of the past and to what extent creative storytelling could make up for any missing material substance. By thoroughly exploring the intricate connections between cultural heritage and artificiality, authenticity and theming.

In order to include intangible cultural heritage as a real and possible touristic attraction one must take into account several interconnected elements. These are: authenticity and the ability to stage the tourist experience; interpretation and presentation of the resources of cultural heritage; the motives for arrival of future and potential tourists. One example is the tradition of trabakula boats in a small town near Split called Krilo Jesenice, a tradition which is over 300 years old. Almost all inhabitants of the town own a wooden boat. Even though the cost of maintaining and buying such boats is exceptionally high, this doesn't stop boatenthusiasts from owning one or even several such boats. There are 110 boats in Krilo Jesenice, and they provide accommodation for 1200 visitors, 700 of which can enjoy a standard which is on par with a five-star hotel. In old times, the people of Krilo used their trabakulas to transport wine from Korčula, Vis, Rogoznica, Primošten, all the way to Trieste. After the end of the Second World War they focused on excavating and transporting sand from the deltas of Cetina. When tourism arrived they refocused once again. The majority of these boats are anchored during the winter and fully utilized during the summer. They are used for organizing daily tours and multi-day cruises. The music coming from the boats serves to attract a multitude of guests. Along with the already present program of cruises on traditional boats, another point of interest is the old method of shipbuilding. The traditional Betina method of shipbuilding on Murter Island has been recognized as a valuable cultural heritage and a shipbuilding school has been opened on the island. During practical classes students participate in the building of traditional ships (gajeta, pasara, leut, guca, batana), learning first-hand from old Betina kalafat masters. The tradition of shipbuilding in Betina starts with the settling of shipbuilding masters from Korčula, as is testified by the surnames of inhabitants. In the beginning of the 17 th century the Republic of Dubrovnik had been the leading naval power in the Mediterranean for around thirty years and it owned a dozen shipyards of which the most important ones were situated on the island of Korčula. The shipbuilding craft and technology were brought to Korčula by Venetian masters who ruled the island in previous years and forever inscribed its name in the history of seafaring (it being the birthplace of Marco Polo). 
A unique way of spending the vacation through creative and hobby tourism could be by restoring an old wooden ship according to traditional methods, or even building a new ship using these methods. The launching of the ship should be marked with celebrations involving the hosts, the local population and the tourists who built the ship together as a team. This would create a truly memorable experience.

From a touristic standpoint, animation is an element of the touristic product in the same way as food or accommodation and it constitutes a part of the total touristic offer. Indeed, it could be said that animation is a form of internal marketing or sale within a destination, seeing how organizing a cultural event makes the touristic product more complex, enriched and competitive (JereLazanski [27]). Touristic animation applies to the free time of guests and tourists within a touristic destination. It keeps them active and they become either active participants or a passive audience of touristic animation programs. Cultural institutions, as well as tourism, interpret animation as a form of communication undertaken in free time, whose purpose is to free tourists from their daily obligations. For sustainable cultural tourism animation signifies a new link between tourism and culture as two important aspects of human life. This result in educating the tourists, who then return because of the cultural programs offered through animation. As a segment of free time, tourism satisfies the needs and expectations of "homo touristicus". It constantly creates new programs linked with culture as a special part of the touristic product (Jere-Lazanski [27]).

A maritime destination therefore should, in the process of creating a touristic milieu, primarily use all of its available resources to physically form its milieu, or rather, its touristic offer. Furthermore, after physically forming a milieu, it should work on creating an impression, on creating a positive emotional reaction to its touristic milieu. This includes enriching its own offer with those elements that directly affect the emotional structure of the tourist and incite in particular those emotions which lead to pleasure. A destination which creates an emotional structure, an emotional touristic milieu, allows the visiting tourist to feel and express his own pleasure.

Emotions within the context of a destination allow the tourist to navigate through such a destination. They offer a dynamic experience of living through its offer and, finally, serve as criteria for its evaluation. If a destination's milieu has a proactive effect on the tourist and his emotional experience during the stay, the satisfaction of such a tourist is ensured. This positive emotional reaction can, with a sufficient degree of intellectual stimulation, result in a realization which inevitably completes the necessary experience and generates a subsequent visit and profit. One can only assume the degree of emotion involved in the animation program of restoring or building a traditional ship, its launching and "baptizing", the first formal group voyage, the discovering of "secrets" of traditional astronomical navigation, learning the wind rose, experiencing the bura and jugo winds, group fishing on the same ship, etc. 


\section{Conclusion}

Experience contains ordinary acts, from the casual to the most eventful occurrences. It embodies both meanings and feelings, the flowering of individual response that continually gravitates toward typicality, so that afterward we can find words to talk about what happened. The project of all of the humanistic disciplines has been to discriminate between the real and the unreal, the genuine and the fake, the realistic and the sentimental or fantastic, the verifiable truth (all those things we call "the facts") and illusions, the misleading, the mystified, and the mythical. Humanists seek insight into life as a means of living more fully themselves, of experiencing it more knowledgeably and more deeply, and thus being able to impart these techniques and this accrued knowledge and wisdom to others. In this paper the personal experiencescape is investigated in such a way that different guest experience dimensions are measured by different research approaches such as "Quality of Experience" QoE, phenomenological, psychometrical and physiometrical approaches. Shown model measures the outcome of the Experience Production and the producer perspective of the Experience Economy with all the different dimensions of Experience Production.

Everyone has experiences that are both unique and typical, but sustainable tourism seems to have a way of organizing these doings so that they may be shared. Implementation of Transformational Experience Production (TEP) into tourism can open for new innovative business concept within the transformational economy and innovative development of sustainable tourism. This proposed theoretical framework of TEP needs, however, to be analyzed in detail for practical implementations, further theoretical verification and finally verified by empirical data. Hopefully, this paper can stimulate such development of the Experience Economy.

Such forms of completely thought out and professionally organized vacations are still rare in Croatia, but they could play a very important role in the expansion and deepening of cultural needs. They could provide more intensive satisfaction to those who have already directed themselves in such a way and at the same time incite it in those who never viewed those needs as important before. The guarantee of sustainability in tourism is closely linked to the encouragement of the development of microenterprises and economic prosperity. The local population itself must identify with the coastal town in which it lives and with the desired development of tourism in order for it to be truly living. If a town is living, tourists will come to it. Accordingly, if the local population can incorporate their daily trades into a touristic activity and in that way present their own way of life and work, the touristic quality of the offer is assured, as well as the quality of life of the native population. Creative tourism can develop faster than other forms of tourism and touristic destinations can present an innovated product relatively quickly and this way be a step ahead of the competition. Creativity is extraordinarily mobile and often based on the transmission of local skills and experiences to tourists in an adequate environment, and it doesn't require a developed infrastructure. 
In order to guarantee sustainability, small scale initiatives which are limited geographically and traditionally should be encouraged, rather than megaprojects. The local population should be given educational opportunities dealing with the theme of local diversity and touristic workers should be further trained. Sustainable development isn't only a synonym for financial durability or the preservation of resources from the environmentalist standpoint; it also refers to the respect that should be given to cultural and social authenticity. Touristic workers should be trained up to the point where they can enrich the touristic product of their destination and improve the quality of interpretation. The ideal touristic worker who will carry out these changes in a touristic destination should be a cultural tourism animator who should be an extroverted, positive individual, conscientious in work, emotionally stable and somewhat more than average intellectually developed (Franjić [28]). The touristic space will therefore be interpreted in a new way, as a spiritual resource which is there to benefit both the tourists who visit it and the local population.

\section{References}

[1] Pine, B.J. and Gilmore, J.H., The experience economy: work is theatre and every business is a stage. Boston Mass: HBS Press, 1999.

[2] Schechner, R., Performance Theory. Routledge, 1988.

[3] Grove, S.J. Fisk, R.P. and Bitner, M.J., Dramatising the service experience: a managerial approach in Advances in Services Marketing and Management (Swartz, T. A. Brown, S. and Bowen, D. eds) Greenwich, CT. JAI Press Inc. [Reprinted in Gabott, M and Hogg, G. (1997) Contemporary Services Marketing: a reader. Dryden Press], 1992.

[4] Shaw, C., Revolutionize Your Customer Experience Basingstoke, Palgrave Macmillan, 2005.

[5] Smith, S. and Wheeler, J., Managing the Customer Experience: turning customers into advocates. Harlow, FT Prentice Hall, 2002.

[6] Nijs, D., Imagineering: Engineering for Imagination in the Emotion Economy. In Creating a Fascinating World, Breda, The Netherlands, NHTV, 2003.

[7] Prahalad, C.K. and Ramaswamy, V., The Future of Competition: Cocreating unique value with customers. Boston, Harvard Business School Press, 2004.

[8] Hirschman, E. and Holbrook, M. Hedonic consumption: emerging concepts, methods and propositions, Journal of Marketing, vol. 46, no. 3, pp. 92-101, 1982.

[9] Abrahams, R.D., Ordinary and Extraordinary Experiences. in: Turner V. (ed) The Anthropology of Experience Chicago, University of Illinois Press, pp 45-72, 1981.

[10] Scitovsky, T., The joyless economy, Oxford University Press, Oxford, 1976.

[11] Beard, J. and Ragheb. M., Measuring Leisure Motivation. Journal of Leisure Research. Vol. 15, No. 3. 1983. 
[12] Csikszentmihalyi, M., Flow: the classic work on how to achieve happiness, Rider paperbacks, 1992.

[13] Ryan, C., (Ed.) The Tourist Experience, Thomson, 1997, 2002.

[14] Schmitt, B., Experiential Marketing: How to Get Customers to sense, feel, think, act and relate to your company and brands. Free Press, 1999.

[15] Harris, R., Harris, K. and Baron, S., Theatrical service experiences, International Journal of Service Industry Management Vol. 14, No. 2: pp. 184-19, 2003.

[16] Carlzon, J. Moments of Truth, Harper Collins, 1987.

[17] Arnould, E.J. and Price, L.L, River Magic: Extraordinary Experience and the Extended Service Encounter. Journal of Consumer Research, 20 (June) 24-35. 1993.

[18] Boswijk, A., Thijssen, T. and Peelen, E., The Experience Economy - a new perspective. Amsterdam: Pearson Prentice Hall, 2007.

[19] Gelter, H., A story of interpretative guiding and experience production. pp. 26-59, 2007. in: IGU -Internordic Guide Education Project Report. Intereg EU Regional development Project. Lappia, Tornio Finland: Vocational College.

[20] Gelter, H., Interpretation and Total Experience Management (TEM) as innovative methods for sustainable nature based tourism - A benchmarking Analysis. Conference paper for the 17th Nordic Symposium in Tourism and Hospitality Research, Lillehammer 25-27. September, 2008.

[21] Jensen, R., The Dream Society. How the coming shift from Information to imagination will transform your business. New York: McGraw-Hill, 1999.

[22] Tarssanen and Kylänen, University of Lapland, www.ulapland.fi/ contentparser.asp?deptid=8073, 2007.

[23] Kozličić, M., Hrvatsko brodovlje, Književni krug, Split, 1993.

[24] Šola, T., Muzejski i razvojni potencijal tradicijskih obrta, Zbornik radova s međunarodne konferencije Tradicijski obrti - izazov za kulturni turizam, održane u Donjoj Stubici 30. i 31. siječnja 2008.g. [Museum and Developmental Potential of Traditional Crafts, A Collection of Works from the International Conference on Traditional Crafts - A Challenge for Cultural Tourism, held in Donja Stubica on 30th and 31st of January 2008] Muzeji Hrvatskog zagorja, Donja Stubica.

[25] Oesterle, C., Staging the Past - Themed Environments in Transcultural Perspective, Internationale Konferenz an der Universität Freiburg, Freiburg, 23. bis 25. April 2009 AHF-Information Nr. 113 vom 27.05.2009 3 AHF-Information. 2009, Nr.113, www.ahf-muenchen.de/ Tagungsberichte/Berichte/pdf/2009/113-09.pdf, 2009.

[26] Holtorf, C., Staging the Past - Themed Environments in Transcultural Perspective, Internationale Konferenz an der Universität Freiburg, Freiburg, 23. bis 25. April 2009 AHF-Information Nr. 113 vom 27.05.2009 3 AHF-Information. 2009, Nr.113, www.ahf-muenchen.de/ Tagungsberichte/Berichte/pdf/2009/113-09.pdf, 2009.

[27] Jere-Lazanski, T., Cultural Animation in Tourism in: Bruce D., Rotariu, I (Eds) (2008) European Cultural Tourism, Past Present and Future: Lectures 
from the Atlas Winter University Sibiu Romania 2007, Alma Mater, Sibu, ISBN 978-973632-395-9 Ch. 4, 2007.

[28] Franjić, R., Quantitative Analysis Carried Out in Croatia between 2008 and 2009 for the Purposes of the Doctoral Thesis 'Intangible Traditional Cultural Heritage and Cultural Tourism - Through Representative Samples', Faculty of Philosophy, Zagreb, Postgraduate Doctoral Course 'Croatian Culture', 2011. 